\title{
Anthropology and Epidemiology: learning epistemological lessons through a collaborative venture
}

\author{
Antropologia e Epidemiologia: aprendendo lições epistemológicas \\ através de um empreendimento colaborativo
}

Dominique Pareja Béhague ${ }^{1,2}$

Helen Gonçalves ${ }^{2}$

Cesar Gomes Victora ${ }^{1,2}$

${ }^{1}$ Department of Epidemiology and Population Health, London School of $\mathrm{H}$ ygieneand Tropical M edicine, Keppel Street, London, WC1E7HT, United Kingdom.

Dominique.Behague@lshtm. ac.uk

${ }^{2}$ Department of Social

M edicine, Federal University of Pelotas, Pelotas, RS,

Brazil.
Abstract Collaboration between anthropology and epidemiology has a long and tumultuous history. Based on empirical examples, this paper describes a number of epistemological lessons wehavelearned through our experience of cross-disciplinary collaboration. Although critical of both mainstream epidemiology and medical anthropology, our analysis focuses on the implications of addressing each discipline's main epistemological differences, while addressing the goal of adopting a broader social approach to health improvement. We believe it is important to push the boundaries of re search collaborations from themorestandard forms of "multidisciplinarity," to the adoption of theoretically imbued "interdisciplinarity." The more wechallenge epistemological limitations and modify ways of knowing, the more we will be able to provide in-depth explanations for the emergence of disease patterns and thus, to problem-solve. In our experience, both institutional support and the adoption of a relativistic attitude are necessary conditions for sustained theoretical interdisciplinarity. Until researchers acknowledge that methodology is merely a human-designed tool to interpret real ity, unnecessary methodological hyper-specialization will continue to alienate one field of knowledge from the other.

Key words Anthropology, Epidemiology, Multidisciplinary, Epistemology
Resumo A colaboração entre Antropologia e Epidemiologia tem uma longa e confusa história. Baseado em exemplos empíricos, o artigo descreve lições epistemológicas aprendidas ao longo da nossa trajetória de colaboração transdisciplinar. Apesar de críticos da Epidemiologia e da Antropologia M édica tradicional e crermos que ambas possuem - objetivo de adotar uma abordagem social à promoção da saúde populacional, enfocamos as implicações de confrontar suas principais diferenças epistemológicas. É importante avaliar os limites da colaboração padrão ("multidisciplinaridade") e destacar a relevância de adotar a "interdisciplinaridade." Quanto mais profissionais de diversas disciplinas convergir e modificar seus modos de saber edesafiar suas posturas epistemológicas, mais poderão dar explicações aprofundadas aos padrões de doenças e solucionar problemas concretos. Em nossa experiência, ambos o suporte institucional e a adoção de uma abordagem realista das limitações epistemológicas das disciplinas são necessários à manutenção do grupo e interdi sci plinaridade teórica. Até que se perceba que a metodologia é uma ferramenta humana criada para interpretar a realidade, a desnecessária hiperespecialização metodológica das disciplinas continuará a alienar um campo do conhecimento do outro.

Palavras-chave Antropologia, Antropologia M é dica, Epidemiologia, Multidisciplinar, Epistemologia 


\section{Introduction}

As applied medical anthropology has become a more central discipline in public health over the last 30 years, challenges and debates relating to cross-disciplinary collaboration, particularly with epidemiologists, have come to the fore ${ }^{1}$. The de mand for anthropological input in public health emerged less from academic epidemiology and more from the limitations that professionals in leading organizations, such as the World Heath Organization and bilateral donor agencies, experienced when relying solely on epidemiology for improving program development, evaluation and implementation ${ }^{2}$. As a result, a certain template for expected ways of collaborating developed. M ost commonly, applied epidemiological projects now generally incorporate sub-studies based on use of "qualitative methods," usually in a so-called "formative phase," to be carried out by anthropologists. In this template, the anthropologist's role has consisted largely of helping epidemiologists adapt standardized measurement tools to specific contexts, providing a descriptive narrative of patients' subjective experiences, or explaining the reasons for the failure of a particular programmatic initiative.

While this form of collaboration is generally deemed useful, in a general sense, the inclusion of qualitative components in public health research initially proved difficult. The merits of including qualitative studies have not always been widely endorsed, and more than once, the authors of this paper noted comments made by colleagues that multidisciplinarity has been engaged in more out of lip-service to donors than real analytical need. For many anthropologists, in turn, the development of applied medical anthropology within the larger public health and epidemiological framework belittled the potential of anthropological contributions, a view that polarized the anthropological community. Whilemany anthropologists embraced the challenge of working in public health, others rightly highlighted that applied anthropology has more often than not been used in a superficial way, devoid of theory and reduced to an over-simplified methods "toolkit"3,4. Fundamental and insurmountable epistemological differencesbetween thetwo disciplines have rarely been acknowledged outside academic settings, to the extent that collaboration between thetwo disciplines has occurred in a parallel, rather than cross-fertilizing, fashion ${ }^{5}$.

Under the pressure of study funders, the authors of this paper began to collaboratein multi- disciplinary projectsin thebeginning of the 1990s, at a time when the inclusion of anthropology and other disciplines in public health had become an entrenched expected norm, even whilethe debates described above had also reached a disharmonious peak. In many regards, we were directly influenced by these debates and certainly experienced a degree of disharmony. From the epidemiologist's perspective, anthropological works werefound to beverbose, excessively anecdotal, inappropriately based on small sample sizes selected according to convenience rather than random allocation. In sum, anthropology was seen to besubjective and un-scientific. The anthropologists in turn, often felt frustration with epidemiology's biological bias, reductionism, tendency to homogenize and simplify reality, lack of theoretical sophistication, and black-boxing of the culture concept, referred to only when needing to explain unexpected or atypical epidemiological findings.

With time and many discussions, however, we discovered that these perceptions of each others' approacheswere inaccurate depictions of our actual epistemological positions. Often, they resulted from a misunderstanding of what each other's discipline was seeking to achieve, emerging from too much attention technical differences relating to methodology and not enough attention to conceptual and analytical similarities. Indeed, critics within both anthropology and epidemiology have highlighted the futility of applying methods without a strong theoretical framework, arguing that the predominant focus on methodological specialization in both fields has inhibited the use of shared conceptual models and theoretical interests $s^{6,7}$. A recent study of professionals engaged in multidisciplinary public health research demonstrates the emergence of parallel debates occurring in both anthropology and public health which call for more critical examination of biomedicine and its dominant role in conceptualization of public health. These developments represent potential common ground that could be capitalized upon in moving towards greater conceptual - rather than methodological - collaboration between disciplines:.

Using empirical examplesfrom our work, this paper aims to describe the epistemological lessons we have learned through our collaboration. Our analysis focuses on the methodological and theoretical implications of actively addressing assumptions regarding our disciplines' main differences, while focusing on the mutual goal of adopting a broader social approach to population health improvement. Although the analysis 
presented below is at times critical of both mainstream epidemiology and medical anthropology, such critiques are not gratuitous but aimed ultimately at enriching multidisci plinary collaboration for the purposes of improving public health practice. As our paper will demonstrate, we believe it is important to push the boundaries of research collaborations from the more standard forms of "multidisciplinarity," or the process whereby professionals of different disciplines participate in a single project, to "interdisciplinarity," or the process where by professionals from distinct disciplines work together to generate novel concepts and integrate different levels and forms of explanation?.

\section{Empirical examples of the collaboration: lessonslearned}

Using examples from our own research, this section will describe a number of areas where we have found convergence between our respective disciplines to be particularly fruitful and focused on theoretical, rather than simply methodological, exchange. Underlying all the forms of exchangewehighlight below is an iterative process, whereby lines of inquiry, methodological developments, conceptual models, and theanalysis and interpretation of data used in both disciplines feed into one-another.

Questionnaire design and improving acceptability of epidemiological surveys

A traditional form of collaboration between thetwo disciplines consists of using ethnographic insight to better develop questionnaires for quantitativesurveys, primarily by improving thewording and social suitability of questions as dictated by formative ethnographic research exploring local taxonomies and illness categories ${ }^{10}$. For example, our research in Northeast Brazil showed that the word "canseira" appropriately captured the "rapid or difficult breathing" concept that characterizes pneumonia in small children with a respiratory infection. Incorporation of this term in the questionnaire - instead of the more complex expression "respiração rápida ou difícil" - helped improve its validity. Throughout our collaboration, we also discovered that anthropological insight can also increase local understanding of the objectives of the research, as well as respondent's acceptability and compliance with the surveyors' requests.
In our work, we took this form of collaboration further, and used it to refine our theoretical and interpretive understanding of phenomenon in question by using ethnographic insight to introduce unexpected questions into our research proposals. Frequently, for example, we have developed new questions to be used in our quantitative designs to help explain larger well-known epidemiological associations. For example, studies of teen pregnancy have frequently found that if the mothers of young girls were themselves teen-mothers, their children are more likely to themsel ves become pregnant as teens. Using an ethnographic approach, we explored the role of the family further and in a more detailed fashion, and found that some parents actively "pressure" their children to engage in serious romantic relationships at an early age. In a subsequent case-control study, we then included this phenomenon as a quantitative measure and found that young girls who had experienced this sort of pressure, as subjectively described by them, were more likely to become pregnant as teen $s^{11}$. Our ethnographic research al so suggested that if a girl's mother had children by more than one father, the risk of teenage pregnancy was increased. This hypothesis, which wasunlikely to havearisen from epidemiological investigation, was confirmed in the quantitative analyses of the whole sample ${ }^{12}$.

Without such an iterative process in which onedisciplineinfluences the thematic content of the other, we are unlikely to have been able to advance our theoretical and explanatory understanding of particular phenomenon in question. However, in our experience, cross-disciplinary fertilization did not simply occur at the level of influencing or improving the content and mechanics of the research process. Rather, as the following sections will demonstrate, we found that the oretical interdisciplinarity was more likely to unfold if weactively challenged each disciplines' epistemological assumptions and limitations.

\section{Use of epidemiological results \\ to frame anthropological studies}

M edical anthropologists often focus their research on describing "discourses" and "worldviews" that develop around a particular concept, disease or widespread phenomenon. Such studies are often based implicitly on the underlying aim of representing the "voices" of marginalized sub-populations, and thus, have tended to produce descriptiveresults that aim to explorelocally salient cultural "constructs." While interesting 
and providing a useful starting point, these studies can prove to be analytically direction-less, as they do not tend to be structured around a specific set of focused questions. Also, because epidemiology has a strong biomedical bias, and because biomedicine is typically interventionist, many epidemiologists have little patience with what they see as unfocussed research that will not lead to concrete public health improvement.

In response to this critique, we found that designing an anthropological study around questions emerging from epidemiological resultsadds a qualitatively different kind of analytical slant to our ethnographic approach. While applied anthropology has not routinely engaged in the use of comparison groups for the purposes of explaining the reasons for health phenomena (and anthropologists' attempts to do so have often been brandished "reductionistic" by their peers), wefound that working al ongside epidemiologists pushed us towards focused exploration and explanation. To better address explanation through the use of comparison groups, we increased our ethnographic sample sizes and used randomly selected sub-samples from the larger epidemiological studies within which we conducted our research (specifically, the 1993 and 1982 cohorts). Random stratified sampling was deemed necessary not to conduct probabilistic analyses, but to learn about the range of experiences among what is in Brazil, a socially and economically highly heterogeneous population and through this, to identify locally salient subgroups for analytical comparison. This sampling scheme also led to the inclusion of both introverted and socially sheltered participants, as well as those who spent very little time in or near their homes, something that certainly a convenience sample, which tends to favor extroverted informants, would not have captured $^{13-16}$.

Using a comparative analytical framework facilitated by this methodological approach, one of our studies, for example, focused on trying to explain the reasons for Brazil's world-renown high cesarean section rates, as found in epidemiological studies, by comparing subgroups of women experiencing and actively seeking both csections and normal birth ${ }^{17,18}$. Similarly, another study explored why certain subcategories of mothers identified in epidemiological studies namely, white women and those with male infants ${ }^{19}$ - wean their children substantially sooner than other women. This study revealed an unexpected set of influences, emerging from themedical establishment's use of growth charts, that push women to wean their children early because of heightened concerns that their infants were not growing well ${ }^{20}$.

The concurrent use of comparison groups in inter-linked epidemiological and anthropological studies has proved particularly useful. For example, one study on the relationship between teen pregnancy and both employment and education used an epidemiological case-control study of teen pregnancy by 18-19 years of age, together with an allied ethnographic study using the same comparative groups. Ethnographic results demonstrate that youth who became pregnant had had school difficulties and failure before falling pregnant. In addition, young girls were found to value forging a lasting bond with their partners, for this also provided them with social status and upward mobility, without having to submit to the rules of educational institutions ${ }^{11,21}$. In terms of practical implications, these analyses suggested that it is not merely the lack of access to or information on contraception that leads to high rates of teen pregnancy, pointing to theneed to take the broader sociocultural dimensions of pregnancy in youth into account. Even if sexual education were effective, this is usually provided between the $5^{\text {th }}$ and $8^{\text {th }}$ grades, and our study showed that girls who are likely to get pregnant areeither dropping out before reaching this grade or are retained in lower grades due to repeated school failure. Therefore, targeting sexual education classes by age rather than grade would definitely make more sense ${ }^{12}$.

Use of ethnography for the interpretation of epidemiological results

Epidemiologistsarebecoming moreand more aware of their discipline's analytical and interpretive limitation $\mathrm{s}^{22}$. Although epidemiology is meant to be rigorously based in hypothesis testing, whereby the associations to be tested are based on clearly postulated and plausiblehypotheses derived either from the literature or clinical knowledge, this is not always the case. Rather, epidemiologists often test multiple hypotheses without being able to fully explain the reasons for the association in question. This is particularly so as epidemiology moves away from studying only biological phenomenon and towards exploring societal patterns and contexst, where causal pathways are likely to be longer, more complex, diverse, and even cyclical ${ }^{23}$.

In this regard, the use of ethnography for the interpretiveenrichment of epidemiological results 
has proved to be fruitful form of interdisciplinary cross-fertilization. Unexpected epidemiological findings particularly benefit from additional anthropological insight when it come to analyzing subsidiary hypotheses and conducting subgroup analysis. In a recent study, for example, we used ethnography to explore and explain possible reasons for the associations established through statistical analysis. Looking specifically at quantitative results from two studies, one on determinants of mental morbidity and the other on age of sexual initiation, we used ethnographic data to elucidate the way that statistical associations are comprised of multiple pathways of influencethat correspond to the unique experiences of specific subgroups. In exploring these pathways, we highlight the importance of an additional set of mediating factors that account for epidemiological results relating to both types of outcomes; these includetheawareness and experience of inequities, young men and women's reactions to the role of violence in everyday life, traumatic life events, increasing social isolation and introversion as a response to life's difficulties, and differing approaches towards socio-psychological maturation ${ }^{24}$. Although these factors are difficult, if not impossible, to capture in a quantitativesurvey, they represent key aspects that should be included in public health initiatives aiming to mental health. In many ways, this goes contrary to thenorm in public health, which tends to structureinterventions according to quantitativeindicators that have been "proven" to becausally salient in epidemiological studies, often without explicitly exploring the underlying phenomenon such indicators are likely to indicate.

Another study similarly explored epidemiologically-established gender differences in physical activity in the 1993 cohort, which showed that girls are more sedentary than boys. In-depth ethnographic research found that for a number of social and cultural reasons, the frequency with which young men socialised outside the school and home settings was higher than for girls. These behaviours weresubsequently asked about in the quantitative survey, and analyses shows that this forms of sociability was associated with a sedentary lifestyle. Further ethnographic work enriched our explanatory understanding of the reasons for this gender difference. Young men areencouraged by their parents to engage in a number of physical activities outside the home in order to develop their masculinity, maturity, and identity. In contrast, young girls' behaviour are actively controlled, to the extent that they are kept inside the home as a way of protecting them against the many dangers that they are perceived to be particularly at risk of experiencing, including physical violence $e^{25}$.

\section{Hypothesis raising, sub-group analysis and effect modification}

The ethnographer's ability to discern differences and patterns according to subgroups represents an underutilized yet important area of convergence with epidemiology. In one of our anthropological studies, we used both qualitativeand quantitativeanalysis to explorehow some women living in shantytowns resist the negative depictions widely made of their social class standing by actively rejecting antenatal care provided in their local primary health care centre. These women considered such services to be a poor substitute for what the wealthy take for granted. Being particularly attuned to the values of upward mobility, several of these women invested their household's scarce resources in travelling to public primary level facilities situated in richer neighbourhoods or tertiary level facilities, and at times, in paying for private sector car ${ }^{26}$. In many ways, this study lay the theoretical ground-work for distinguishing between subgroups of shantytown dwellers according to key attitudes relating to economic inequities, upward mobility, and normativesociety.

The ethnographic focus on discerning social patterns according to subgroups al so holds great potential for the epidemiological exploration of effect modification. A recent analysis using ethnographic insight, for example, found that the statistical association between early teen pregnancy and mental morbidity in adulthood not only holds after controlling for confounders, but is modified by social class, such that the negative impact of pregnancy on mental morbidity is significantly more pronounced amongst the poor than therich. The use of ethnographic case-studies in this analysis enabled us to clearly explorethemechanisms that account for these epidemiological findings. The ethnographic study found that the association between pregnancy and mental morbidity is more pronounced amongst a subgroup of poor women who feel marginalized from mainstream society. These women are highly politicised and particularly sensitive to the social stigma associated with teen pregnancy in poor youth. Because of this, some reject what they identify as upper class values, which includes the view that teenpregnancy should beavoided. For these girls, teen 
pregnancy represents a desired state that reaffirms their prideas members of theworking class. Even so, these girls suffer considerable psychological strain ensuing from thesocial prejudice that their reproductive decisions stimulate ${ }^{27}$.

Similarly, another study on the relationship between pacifier use and breastfeeding duration used focused comparative ethnography to guide epidemiological subgroup analysis and consideration of effect modifiers. Ethnographic insight proved fundamental to teasing out whether or not pacifier use was causality related to breastfeeding duration, and to discern in which subgroups of women the relationship proved to be more strongly associated ${ }^{28}$. Although the ethnographic study was based on a small sample, the social patterning it uncovered guided the epidemiological identification of effect modifiers, bringing a level of analytical nuance to the epidemiological analysis that would have otherwise gone unnoticed. In this cases, it is particularly interesting to note that - whereas epidemiological studies alone showed a strong association between pacifier use and short breastfeeding duration the combination with ethnographic analysessuggested that association was not causal. After this study was published, a randomized controlled trial supported the lack of a causal association ${ }^{29}$.

Contrary to common depictions of the limitations of ethnographies based on small samplesizes, these studies show the power that in-depth anthropological analysis has for discerning patterns within a small sample size, which can later be confirmed in quantitativesurvey work. In our work, we havefound that a remarkably high proportion of the effect modifications (or interactions) suggested by small ethnographic studies are likely to be confirmed as statistically significant in epidemiological analyses.

These experiences demonstrate the importance of having in-depth knowledge of local conditions, practices and realities for improving the interpretive caliber of epidemiological research. Indeed, a growing concern amongst social epidemiologists no longer working within a biological conceptual framework is the relativelack of a rigorous conceptual basis upon which epidemiological hypotheses and analyses are conducted. Related to this is theneed somesocial epidemiologists identify to ground their work more fully within local contextual knowledge ${ }^{7,30-32}$.

\section{Discussion}

Our experiences with theabovecollaborativeventures has not al ways been easy, nor has it developed without some degree of professional risk. While a template of sorts was developed in early days for the combined use of qualitative and quantitative methods, those seeking to engage in conceptual interdisciplinarity have been required to chart new ground. This not only brings with it a number of communicative difficulties, it holds important implications for publication. Although a number of epidemiological and public health journals now accept and encourage publication of studies using qualitative components, this is certainly a minority occurrence, and still heavily focused on the addition of "qual itativemethods," rather than truedisciplinary theoretical exchange. Furthermore, many public health journal require studies reporting on ethnographic findings to starkly separatea "neutral" description of results from their discussion, even though this is antithetical to the analytical and interpretive frameworks most often required in anthropology. Journals publishing in medical and social anthropology, in turn, have as of yet failed to fully explore the benefits of considering anthropological studies that include quantitative analyses. Remarkably few journals are rigorous on both accounts, to the extent that in our experience, reviewers' comments can often be quite polarized, depending on their disciplinary orientation. In an amusing albeit somewhat offensive review, one of our paper combining ethnographic and epidemiological results was described as follows "this material is thrown together as a Spanish paella in that 'anything that ever swum the seas' can go in it: it is tasty; but no one knows what is in it or its nutritional value."

To remedy this constraint, we believe greater attention should be given to the conceptual and theoretical bases for interdisciplinary exchange, a type of exchange that requires an explicit consideration of the epistemological boundaries of each of our respective disciplines. In our experience, engaging with substantive analytical questions centered our discussion around conceptual models, and charting the hierarchical pathways of influence from one set of social determinants to various health outcomes in question ${ }^{33}$. Epistemological convergence was facilitated through a three specific foci which were in actuality facilitated, rather than inhibited, by the "applied" nature of our work. 
First, the need in public health is to not simply describe phenomena, but to explain the reasons for their appearance and to propose ways to changethem. This requirement of developing research questions within a problem-solving framework demands a more sophisticated and explicit theoretical orientation, onethat is geared towards generating understandings of causality and mechanisms of change. To fulfill this objective, both methodological and epistemological modifications are required ${ }^{34}$, to which both epidemiology and anthropology have the potential to contribute. In our view, so central is this type of interdisciplinary cross-fertilization that most of our studies - even those headed by anthropologists - now comprise both an epidemiological and anthropological approach.

Second, while discussions around methods often constituted the starting-point of our collaboration, our mutual interest in explanation lead us to focus less on methodological refinement and specialization, and moreon challenges in the interpretation of data and meaning attributed to our analytical conclusions. As some authors have claimed, debates around the limitations of statistical measurements have severely restricted theoretical developments. Authors critique the excessive amount of attention that is often given to developing more specific and sophisticated measurement techniques at the expense of using good but simple "summary measures" to advance theoretical premises and hypotheses ${ }^{35,36}$. As Frohlich et al. argue, the fundamental barrier to better exploring the relationship between structure, local context and ill-health is the dominance of black box "risk factor" epidemiology that couches theoretical limitations under methodological sophistication ${ }^{37}$. Similar critiques have been leveled at applied anthropologists, who have developed highly sophisticated methodological how-to manuals for conducting formative anthropological research within specific disease programs, often putting forth intricate interviewing techniques (e.g. pile sorting or ranking) that in fact do not originally belong to anthropology and that do little to advance understandings of social changet.

Third, as the focus moves away from describing the differences between the two disciplines solely in terms of methods, unhelpful dichotomies are deconstructed. As some authors have pointed out, stereotyped dichotomies often put forth in debates on interdisciplinary collaboration - including deductive-inductive, natural-artificial, specific-generalisable- are not necessari- ly (or simplistically) determined by methods used $^{38,39}$. Hammersely, for example, has shown how in-depth case study methods and large-scale multivariate survey research can - depending on how they are used - share the similar underlying aim of developing a conceptual model on how variables are related, taking time and place into consideration ${ }^{40}$. In other words, open-ended qualitative methods can be just as reductionistic as quantitative surveys, and a cross-sectional survey can be equally as inductive as participantobservation.

\section{Conclusion}

Our concern with highlighting the interdisciplinary basis upon which epistemological assumptions can be challenged and collaboration improved is not an academic exercise, but one that has significant consequences for public health research and practice. The moredisciplines can converge and modify standardized ways of knowing, themorethey will beableto providein-depth and contextually sensitive explanations for the emergence of disease-patterns and thus, to problemsolve.

Despite many advances in multidisciplinary collaboration, therelationship between epidemiology and anthropology has yet to develop fully. Today, there are a great number of useful publications on how anthropology can better contribute to epidemiology, than vice versa ${ }^{1}$. This probably reflects the excessive focus that exists on the exchange of methods, the relative subordinate position of anthropology to epidemiology within public health, and the subsequent need anthropologists have to demonstrate and prove their discipline's relevance. To modify this and other power balances, many questions regarding cross-disciplinary fertilization still need answering. What contributions can epidemiology still make to anthropology? How would an anthropology influenced by epidemiology be different from an epidemiology influenced by anthropology? What professional and institutional conditions would be necessary for further developing a conceptual and interdisciplinary - rather than simply multidisciplinary - approach to researching health problems?

In our experience, the importance of institutional support for in-depth and sustained interdisciplinary collaboration cannot be under-estimated. At both the Department of Social M edicine (DSM) at the Federal University of Pelotas 
and the London School of Hygiene and Tropical Medicine (LSHTM) (two institutions that have influenced each-other positively with regards to our own interdisciplinary collaboration), significant efforts have been madeto include and maintain marginal disciplines such as anthropology. At the DSM , theonly opening for a junior faculty position in several years was allocated to an anthropologist, quite a development in a department hitherto restricted to medical doctors and epidemiologists. At the LSHTM , in turn, thenumbers of anthropologists who have joined and re mained at the school has quadrupled since the late 1980 s.

In addition to institutional factors, a fundamental quality contributing to the success of our collaboration has been the adoption of a relativistic and open stance regarding the epistemolog- ical limitations of both disciplines. In our experience, such relativism initially manifested itself in a mutual interest in devoting considerable time to learning about the methods and terminology of each-others' disciplines, but with time, this learning process quickly lead to the development of a fruitful and yet critical perspective on the limits of disciplinary specialization for generating new knowledge. As Van der Geest has argued, disciplinary specialization and "ethnocentrism" is at the core of inhibited cross-disciplinary re$\operatorname{search}^{41}$. Until each discipline demonstrates greater humility and realizes that disciplines are merely humanly-designed tools to study and interpret and explain reality, unnecessary hyper-specialization will continue to alienate one field of knowledge from another.

\section{Collaboration}

DP Béhague conducted the literature search and wrote the paper. $\mathrm{H}$ Gonçalves commented on a draft of the paper, and wrote certain sub-sections of the paper. CG Victora commented on a draft of the paper, and edited sections of the paper. 


\section{Acknowledgements}

The research upon which our collaboration has developed has been supported by the European Union, the National Program for Centers of Excellence- PRONEX (Brazil), Conselho Nacional de Desenvolvimento Científico e Tecnológico $(\mathrm{CNPq})$, and the M inistry of $\mathrm{H}$ ealth (Brazil), the PanAmerican Health Organization, the World Health Organization, Rio Grande do Sul State Research Foundation (FAPERGS), and The Wellcome Trust. At earlier points, training fellowships were provided by The US N ational Science Foundation (for DP Béhague) and the Coordenação deAperfeiçoamento dePessoal deNível Superior (for H Gonçalves). D Béhague was supported by a Wellcome Trust post-doctoral fellowship during the completion of some of the research cited in this paper, as well as during the preparation of this manuscript.

\section{References}

1. Trostle JA. Epidemiology and Culture. Cambridge: Cambridge University Press; 2005.

2. de Zoysa I, Habicht J, Pelto G, M artines J. Research steps in the development and evaluation of public health interventions. Bulletin of the World Health Organization 1998; 76(2):127-133.

3. Scrimshaw S, Hurtado E. Rapid Assessment Procedures for Nutrition and Primary Health Care: Approaches to Improving Programme Effectiveness. LoS Angeles: UCLA Latin American Center; 1987.

4. Bennett FJ. Qualitative and Quantitative M ethods: In-Depth or Rapid Assessment? [editorial]. Soc Sci M ed 1995; 40(12):1589-1590.

5. Dunn $F$, Janes C. Introduction: Medical Anthropology and Epidemiology. In: Jaines C, Stall R, Gifford S, editors. Anthropology and Epidemiology: Interdisciplinary Approaches to the Study of $\mathrm{H}$ ealth and Disease. Dordrecht: D. Reidel Pub Company; 1986. p. 3-34.

6. Agar M. Recasting the "Ethno" in "Epidemiology". Medical Anthropology 1996; 16:361-403.

7. Krieger N. Epidemiology and the Web of Causation: Has Anyone seen the Spider? Soc Sci M ed 1994; 39(7):887-903.

8. Napolitano $D$, Jones $C$. Who needs 'pukka anthropologists'? A study of the perceptions of the use of anthropology in tropical public health research. Tropical Medicine and International Health 2006; 11(8):1264-1275.

9. Rodgers I, Scaife M, Rizzo A. Interdisciplinarity: An Emergent or Engineered Process? In: Derry S, Gernsbacher, MA, Schunn, CD, editor. Interdisciplinary Collaboration: An Emerging Cognitive Science. London: Routledge; 2005. p. 265-86.

10. Lombardi C, Kendall C. Brazil: a RAP survey. Dialogue on Diarrhoea 1998; 39:4.

11. Gonçalves H, Gigante D. Work, schooling, and reproductive health: an ethno-epidemiological study of adolescent women belonging to a birth cohort. Cad Saúde Pública 2006; 22(7):1459-1469.

12. Gigante D, Victora C, Goncalves H, Lima R, Barros F, Rasmussen K. Risk factors for childbearing during adolescence in a population-based birth cohort in southern Brazil. Rev Panam Salud Publica 2004; 16(1):1-10.

13. Béhague $D$, Victora $C$, Barros F. Consumer demand for caesarean section deliveries in Brazil: informed decision-making, patient choice or social inequality? A population-based birth cohort study linking ethnographic and epidemiological methods. BM J 2002; 324(20): 942-944.

14. Béhague D. The Shaping of Adolescent Pathology in the Wake of Brazil's New Democracy [doctoral]. M ontreal: M cGill University; 2004.

15. Victora CG, Barros FC, Lima RC, Behague DP, Gonçalves H, Horta BL, Gigante DP, Vaughan JP. The Pelotas (Brazil) Birth Cohort Study, 1982-2001. Cad Saúde Pública 2003; 18(5):1241-1256.

16. Victora $C$, Araújo C, Menezes A, Hallal P, Vieira M, Neutzling M, Gonçalves H, Valle NC, Lima RC, Anselmi L, Behague D, Gigante DP, Barros FC. M ethodological Aspects of the 1993 Pelotas (Brazil) Birth Cohort Study. Rev. Saúde Pública 2006; 40(1):39-46. 
17. Béhague $D$. Beyond the simple economics of cesarean section birthing: women's resistance to social inequality. Culture, M edicine and Psychiatry 2002; 26(4):473-507.

18. Barros F, Vaughan J, Victora C, Huttly S. Epidemic of Caeserean sections in Brazil. Lancet 1991; $338(20): 167-169$.

19. Barros F. Breastfeeding and socioeconomic status in Southern Brazil. Acta Pediatr Scand 1986; 75:558-562.

20. Béhague $D$. Growth Monitoring and the Promotion of Breastfeeding. Soc Sci M edicine 1993; 37(12):15651578.

21. Goncalves H. Aproveitar a vida: um estudo antropológico sobre valores, juventudes e gravidez em uma cidade do interior [tese]. Porto Alegre (RS): Departamento de Antropologia Social, UFRGS; 2004.

22. Black N. Evidence based policy: proceed with care. BMJ 2001; 323(4):275-279.

23. Victora C, Habicht J, Bryce J. Evidence-based public health: moving beyond randomized trials. Am J Public H ealth 2004; 94(3):400-405.

24. Béhague $D$, Gonçalves $H$. Explorando mecanismos de causalidade: colaboração entre Antropologia e Epidemiologia. Rev. Saúde Pública. In review 2008.

25. Gonçalves $\mathrm{H}, \mathrm{H}$ allal $\mathrm{PC}$, Amorim TC, Araujo $\mathrm{CL}$, Menezes AM. Efeito de fatores sócio-culturais sobre o nível de atividade física na adolescência. Rev Panam Salud Publica 2007; 22(4): 246-256.

26. Béhague $D$, Gonçalves $H$, Dias da Costa J. The making of medicine for the poor: primary health care interpretations of professionals, patients and politicians in Pelotas, Brazil. Health Policy and Planning 2002; 17(2):131-143.

27. Béhague D, Goncalves H, Kirkwood B, Gigante D, Victora $C$. Teen pregnancy and mental morbidity in early adulthood: stigma and class struggles amongst youth in Pelotas, Brazil. British Journal of Psychiatry. In review 2008.

28. Victora C, Behague D, Barros F, Olinto M, Weiderpass E. Pacific Use and Short Breastfeeding Duration: Cause, Consequence, or Coincidence? Pediatrics 1997; 99(3):445-453.

29. Kramer $M$, Barr R, Dagenais $S$, Yang $H$, Jones $P$, Ciofani $L$, Jane F. Pacifier use, early weaning, and cry/fuss behavior: a randomized controlled trial. JAM A 2001; 286 (3): 322-326.
30. Davey Smith G, Ebrahim S. Epidemiology - is it time to call it a day? International Journal of Epidemiology 2001; 30:1-11.

31. Krieger N. Commentary: Society, biology and the logic of social epidemiology. International Journal of Epidemiology 2001; 30:44-46.

32. M cPherson K. Commentary: Epidemiology? Keep it broad and deep. International Journal of Epidemiology 2001; 30:48.

33. Victora $C$, Huttly $S$, Fuchs $S$, Olinto $M$. The role of conceptual frameworks in epidemiological analysis: A hierarchical approach. International Journal of Epidemiology 1997; 26(1):224-227.

34. Baum F. Researching Public Health: Behind the Qualitative-Quantitative M ethodological Debate. Soc Sc M edicine 1995; 40(4):459-468.

35. Williams G. The determinants of health: structure, context and agency. Sociology of Health and IIIness 2003; 25 (Sp):131-154.

36. Prandy K. Class, stratification and inequalities in health: a comparison of the Registrar General's Social Classes and the Cambridge Scale. Sociology of Health and IIIness 1999; 21:466-484.

37. Frohlich $\mathrm{KL}$, Corin E, Potvin L. A theoretical proposal for the relationship between context and disease. Sociology of $\mathrm{H}$ ealth and IIIness 2001; 23(6):776797.

38. Hammersley M . D econstructing the Q ualitative Q uantitative Divide. What's Wrong With Ethnography? London: Routledge; 1992.

39. Johnson A, Johnson OR. Quality into Quantity: On the M easurement Potential of Ethnographic Fieldnotes. In: Sanjek R, editor. Fieldnotes: The Makings of Anthropology. Ithaca: Cornell University Press; 1990. p. 160-86.

40. Hammersley M. The Logic of Theory-Testing in Case Study Research. What's Wrong With Ethnography? London: Routledge; 1992.

41. Van der Geest S. Overcoming Ethnocentrism: How Social Science and Medicine Relate and Should Relate to One Another. Soc Sci Medicine 1995; 40(7):869-872. 